\title{
Multielemental Characterization of Airborne Particulate Matter Collected in Bucharest and Tokushima by Inductively Coupled Plasma Mass Spectrometry and Inductively Coupled Plasma Atomic Emission Spectrometry
}

\author{
Tomoki Yabutani, ${ }^{*} \dagger$ Yumi NaKamoto, ${ }^{*}$ Ryoji Yamanouchi, ${ }^{*}$ Le Thi Xuan Thuy, ${ }^{*}$ \\ Kei-ichiro Murai,* Junko Motonaka,* Mitsuharu OGaki,* Madelene Anette Dancila, ** \\ Rodica Stanescu, ** and Marinela Plesca*** \\ *Department of Chemical Science and Technology, Institute of Science and Technology, \\ The University of Tokushima, 2-1 Minamijosanjima, Tokushima 770-8506, Japan \\ **Department of Inorganic Technology and Environmental Protection, Faculty of Industrial Chemistry, \\ Polytechnic University of Bucharest, Bucharest 011061, Romania \\ ***Regional Environmental Protection Agency of Bucharest, Aleea Lacul Morii, No1 Bucharest 060841, \\ Romania
}

\begin{abstract}
Airborne particulate matter (PM) collected in Bucharest (Romania) and Tokushima (Japan) was comprehensively characterized through multielemental analysis by ICP-MS to the PM samples. Prior to an elemental characterization of the sample, a multielemental determination method composed of acid digestion $\left(\mathrm{HClO}_{4} / \mathrm{HNO}_{3} / \mathrm{HF}\right.$ or $\left.\mathrm{H}_{2} \mathrm{O}_{2} / \mathrm{HNO}_{3} / \mathrm{HF}\right)$ and inductively coupled plasma mass spectrometry/inductively coupled plasma atomic emission spectrometry (ICP-MS/ICP-AES) was established to analyze a certified reference material of vehicle exhaust matter (NIES No. 8) for verifying the method. As the results, 39 elements in the certified reference material could be determined. They were a good agreement with the certified and reference values for $\mathrm{HClO}_{4} / \mathrm{HNO}_{3} / \mathrm{HF}$ acid digestion. Chalcophile elements, such as cadmium, antimony, and lead in Bucharest showed higher enrichment factors than those in Tokushima.
\end{abstract}

(Received September 17, 2009; Accepted December 24, 2009; Published March 10, 2010)

\section{Introduction}

There have been global concerns about pollution of the urban atmosphere by airborne particulate matter (PM). The chemical characterization of PM is important to assess the environmental risk on human health, and to identify their emission sources. ${ }^{1}$ Therefore, it is desirable to determine as many elements in PM as possible. ${ }^{2-5}$

Romania joined the European Union at the beginning of 2007. The atmospheric and aquatic environments of Romania have been drastically changing for the past few years. Therefore, Romania is a very good place to track changes in the atmospheric, aquatic, and urban environment and to assess the effectiveness of the environmental protection policy of the Romania government. ${ }^{6}$ Bucharest is the capital city of Romania, with a population of over 2 million. In Bucharest, atmospheric pollution remains one of the most severe problems. Cercasov et al. reported that the concentration trends of 17 elements in PM samples, which were collected with an Andersen sampler at the outskirt of Bucharest measured by neutron activation analysis and X-ray fluorescence analysis, were compared with those at Stuttgart in Germany. ${ }^{7}$ However, recent systematical studies for PM in the atmospheric environment of Romania have been a very few for over ten years. ${ }^{7,8}$ Because the small

† To whom correspondence should be addressed.

E-mail: yabutani@chem.tokushima-u.ac.jp amount of data was caused by limited availability of the air monitoring infrastructure in Romania due to economical and political disorder for over 10 years since the democratic revolution in 1989. Thus, we conducted a pilot study concerning for collection and elemental characterization of over 30 elements in airborne particulate matter at Bucharest in 2005. An important goal of this study was to estimate the concentration of metals in Bucharest, and to compared with previous other studies of air pollutants of metals with the result of this study.

In this work, we tried to characterize PM samples collected in Bucharest and Tokushima based on a multielemental analysis by inductively coupled plasma mass spectrometry (ICP-MS) and inductively coupled plasma atomic emission spectrometry (ICP-AES). The scheme involving acid digestion and the measurement of ICP-MS/ICP-AES was optimized by using NIES No. 8 Vehicle Exhaust Particulate. To our best knowledge, there have not been publications concerning for determination of over 30 elements, including all rare-earth elements for NIES No. 8.

\section{Experimental}

\section{Instruments and reagents}

A Shimadzu ICPM 8500 with a quadrupole mass filter and a glass concentric nebulizer (flow rate $500 \mu \mathrm{min}^{-1}$, Glass Expansion, USA) was used for trace element analysis. Major elements were determined by ICP-AES (SPS 1500 VR, Seiko 
Instruments, Chiba, Japan). The typical operating conditions of the ICP-MS and ICP-AES were similar to those used in previous work. ${ }^{9,10}$ Purified water used throughout the present experiment was prepared by a Milli-Q system (Millipore Gradient, Millipore, Tokyo, Japan).

Multielement standard solutions for standardization of the calibration curves were prepared by mixing single-element standard stock solutions $\left(1000 \mathrm{mg} \mathrm{dm}^{-3}\right)$ of each element for atomic absorption spectrometry, purchased from Kanto Chemicals (Tokyo, Japan) and Wako Chemicals (Osaka, Japan). PTFE membrane filters (pore size, $0.45 \mu \mathrm{m}$ ) and polycarbonate filter (pore size, $0.40 \mu \mathrm{m}$ ) were also purchased from Nihon Millipore Kogyo (Tokyo, Japan) and Advantec (Tokyo, Japan), respectively. A vehicle exhaust particulate certified reference material of NIES No. 8 issued from National Institute for Environmental Study (Tsukuba, Japan) was used to certify the analytical method for the determination of PM samples.

The PM samples were collected by a low-volume Andersen sampler (AN-200, Shibata Scientific Tech. Ltd., Japan). The equipment and supplies were brought from Tokushima to Bucharest. The PM samples were collected by the low-volume Andersen sampler on the rooftop ( $\mathrm{ca} .30 \mathrm{~m}$ height) of a building of The University "Politehnica" of Bucharest (UPB, $26^{\circ} 02^{\prime} \mathrm{E}$, $44^{\circ} 26^{\prime} \mathrm{N}$ ) and the rooftop ( $\mathrm{ca} .40 \mathrm{~m}$ of the height) of the University of Tokushima $\left(134^{\circ} 33^{\prime} \mathrm{E}, 34^{\circ} 04^{\prime} \mathrm{N}\right)$ at a flow rate of $27.3 \mathrm{dm}^{3} \mathrm{~min}^{-1}$. The PM samples were collected on polycarbonate filter paper (diameter, $80 \mathrm{~mm}$ ) for two weeks in 2005. The PM samples were classificated into 7 size ranges. The size ranges were $0.43-0.65,0.65-1.1,1.1-2.1,2.1-3.3$, $3.3-4.7,4.7-7$, and $7-11 \mu \mathrm{m}$. After sampling, the filter was stored in a desiccator.

\section{Digestion of PM samples}

The PM and NIES No. 8 samples were digested by acid combinations of $\mathrm{HClO}_{4}(60 \%$, for analytical grade, Kanto Chemicals) $/ \mathrm{HNO}_{3}$ (69\% EL grade; Kanto Chemicals)/HF (50\%, for Electronics, Morita Chemical Industries Co., Japan) or $\mathrm{H}_{2} \mathrm{O}_{2}$ (30\%, for atomic absorption spectrometry, Kanto Chemicals) $/ \mathrm{HNO}_{3} / \mathrm{HF}$ under microwave radiation.

In the case of an analysis of NIES No. 8, a sample of $0.3 \mathrm{~g}$ was taken into a tetrafluoromethoxyl polymer (TFM) vessel. After $5 \mathrm{ml}$ of $\mathrm{HNO}_{3}, 1 \mathrm{ml}$ of $\mathrm{HF}$ and $2 \mathrm{ml}$ of $\mathrm{HClO}_{4}$ or $\mathrm{H}_{2} \mathrm{O}_{2}$ were added into it; the microwave program was performed in accordance with a recommended program of the microwave oven from the manufacturer (Ethos TC, Milestone General, Kawasaki, Japan). The HF in the solution after microwave digestion was removed by heating it with an infrared lamp into a clean vessel on a hot plate. A $10-\mathrm{ml}$ volume of $2 \mathrm{~mol} \mathrm{dm}^{-3}$ $\mathrm{HNO}_{3}$ was added and heated at $140^{\circ} \mathrm{C}$ to dissolve the residues on the hot plate. The internal standard elements (In, Re) were added in the digested solution to be both $10 \mathrm{ng} \mathrm{ml}^{-1}$ in $15 \mathrm{ml}$ of the final sample solution. For the PM sample, 3 pieces of 1/12-cut polycarbonate sheet from the Andersen sampler were set into a TFM vessel. The digestion procedure was the same in the NIES No. 8 analysis mentioned above.

\section{Results and Discussion}

\section{Determination of metals in NIES No. 8}

NIES No. 8 was analyzed to verify the analytical procedures, including sample digestion used by $\mathrm{HClO}_{4} / \mathrm{HNO}_{3} / \mathrm{HF}$ or $\mathrm{H}_{2} \mathrm{O}_{2} / \mathrm{HNO}_{3} / \mathrm{HF}$ and the ICP-MS/ICP-AES measurements. The analytical results at the two types of acid combination are summarized in Table 1. In Table 1, the analytical results are shown as the mean values and the standard deviation, which were estimated from four independent experiments. As can be seen in Table 1, 39 elements could be determined by these methods. The analytical results of $\mathrm{Ca}, \mathrm{Fe}, \mathrm{Al}, \mathrm{Zn}, \mathrm{Mg}, \mathrm{Ti}, \mathrm{Ba}$, $\mathrm{Sr}, \mathrm{Cu}, \mathrm{Mn}, \mathrm{Ni}, \mathrm{W}, \mathrm{Sn}, \mathrm{Sb}, \mathrm{Co}, \mathrm{REEs}, \mathrm{Ag}, \mathrm{Pt}, \mathrm{Rh}$, and $\mathrm{Au}$ obtained with $\mathrm{H}_{2} \mathrm{O}_{2} / \mathrm{HNO}_{3} / \mathrm{HF}$ acid digestion were lower than those with $\mathrm{HClO}_{4} / \mathrm{HNO}_{3} / \mathrm{HF}$ acid digestion. On the other hand, the blank values of almost all elements with $\mathrm{H}_{2} \mathrm{O}_{2} / \mathrm{HNO}_{3} / \mathrm{HF}$ acid digestion were less than that of the $\mathrm{HClO}_{4} / \mathrm{HNO}_{3} / \mathrm{HF}$ acid digestion. This may be due to some impurity from the reagents. The analytical results with $\mathrm{HClO}_{4} / \mathrm{HNO}_{3} / \mathrm{HF}$ acid digestion were in better agreement with the certified and literature values than those with $\mathrm{H}_{2} \mathrm{O}_{2} / \mathrm{HNO}_{3} / \mathrm{HF}$ acid digestion. ${ }^{11}$ It is known that $\mathrm{HClO}_{4}$ has a highly oxidative ability, and its high boiling point prevents the loss of such insoluble species as fluorine salts among the dryness process to remove HF. Almost all of the rare-earth elements and noble metals ( $\mathrm{Au}, \mathrm{Pt}$ and $\mathrm{Rh})$ of the certified reference material were firstly determined in the present work. The relative standard deviations (RSDs) of the elements with the certified values, except for $\mathrm{Cd}$, were within $10 \%$. Accordingly, $\mathrm{HClO}_{4} / \mathrm{HNO}_{3} / \mathrm{HF}$ acid digestion was employed for the simultaneous preconcentration of trace elements in PM samples.

\section{Concentrations and enrichment factors of metals in PM samples}

The analytical results of a multielemental analysis of a PM sample collected at UPB in 2005 are given in Table 2. Over 30 elements could be determined. However, Ca, Y, Gd, Tb, Yb, Ho, $\mathrm{Lu}, \mathrm{Cr}, \mathrm{Co}, \mathrm{Rh}, \mathrm{Ni}, \mathrm{Pt}, \mathrm{Au}, \mathrm{Ag}$ and $\mathrm{Zn}$ showed low reliabilities due to their relatively high blanks caused from the impurity of the filter for the sample collection or variability in the measurement around the detection limit of ICP-AES/ICP-MS.

The total concentrations of $\mathrm{Pb}\left(43.9 \mathrm{ng} \mathrm{m}^{-3}\right)$ and $\mathrm{Sb}$ $\left(1.73 \mathrm{ng} \mathrm{m}^{-3}\right)$, which were obtained as a summation of the concentrations in all of the size fractions listed in Table 2, were significantly lower than those data $\left(\mathrm{Pb} 334-460 \mathrm{ng} \mathrm{m}^{-3}, \mathrm{Sb}\right.$ $6.7-10.7 \mathrm{ng} \mathrm{m}^{-3}$ ) in the PM sample observed at Bucharest in 1998, reported by Cercasov et al. ${ }^{7}$ The decrease of $\mathrm{Pb}$ was due to a decreasing use of leaded gasoline, which had been banned at the end of 2004. ${ }^{12}$ The EFs in the PM samples collected at Bucharest in 2005 and Tokushima in 2006 are summarized in Fig. 1. $\mathrm{EF}_{\mathrm{x}}=(X / \mathrm{Al})$ sample/ $(X / \mathrm{Al})$ crust, where $X$ is the concentration of the element of interest and $\mathrm{Al}$ for normalization. Aluminum is one of the major elements in the crust, and is represented as the reference elements of natural origin. ${ }^{13}$ The EFs of lithophile elements, such as Ca, Sr, Y, REEs, and Mn, were low, and almost similar levels in both of the particle sizes and the cities. On the other hand, the chalcophile elements, such as $\mathrm{Sb}, \mathrm{Pb}$, and $\mathrm{Cd}$ exhibited high enrichment factors in all of the size fractions and cites. The results given in Fig. 1 also show higher EFs of the chalcophile elements in the small particle size $(2.1-3.3 \mu \mathrm{m})$ than those in the large particle size $(7-11 \mu \mathrm{m})$. The EFs of $\mathrm{Pb}, \mathrm{Cd}$, and $\mathrm{Sb}$ in the $2.1-3.3 \mu \mathrm{m}$ size range were 470, 590, and 1500, listed in Table 2. These EFs at Bucharest were higher than those at Tokushima, and approximately similar to those at Tokyo $(2-11 \mu \mathrm{m}$ of the PM size fraction, 1995 - 2006 average, reported by Sato et al.). ${ }^{14}$ The high EFs of the chalcophile elements may reflect huge emission of heavy metal from automobiles and industry due to poor removal systems of pollutants in Romania, since these chalcophile elements are easily evaporated in particles during the combustion of waste and fuel. 


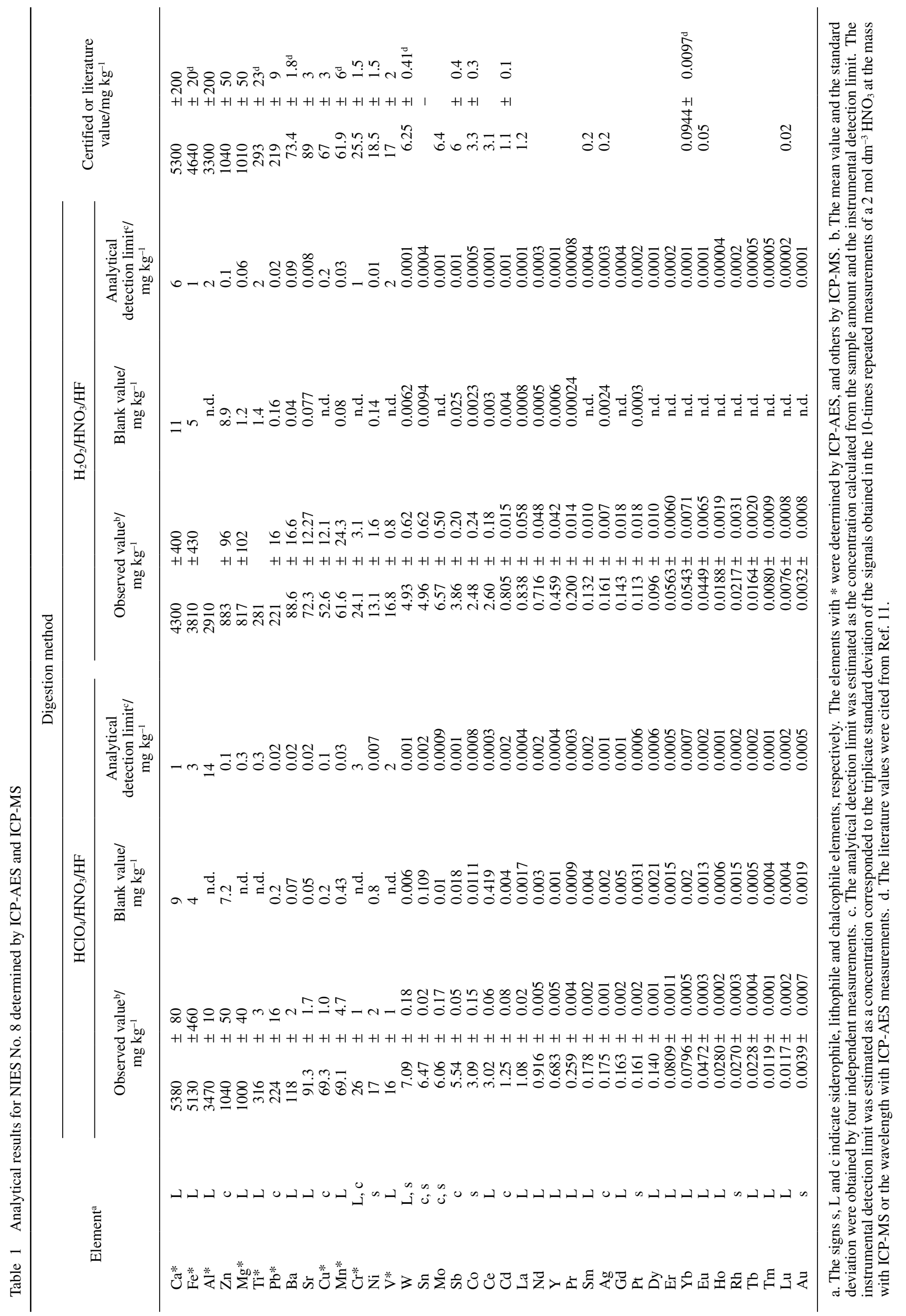




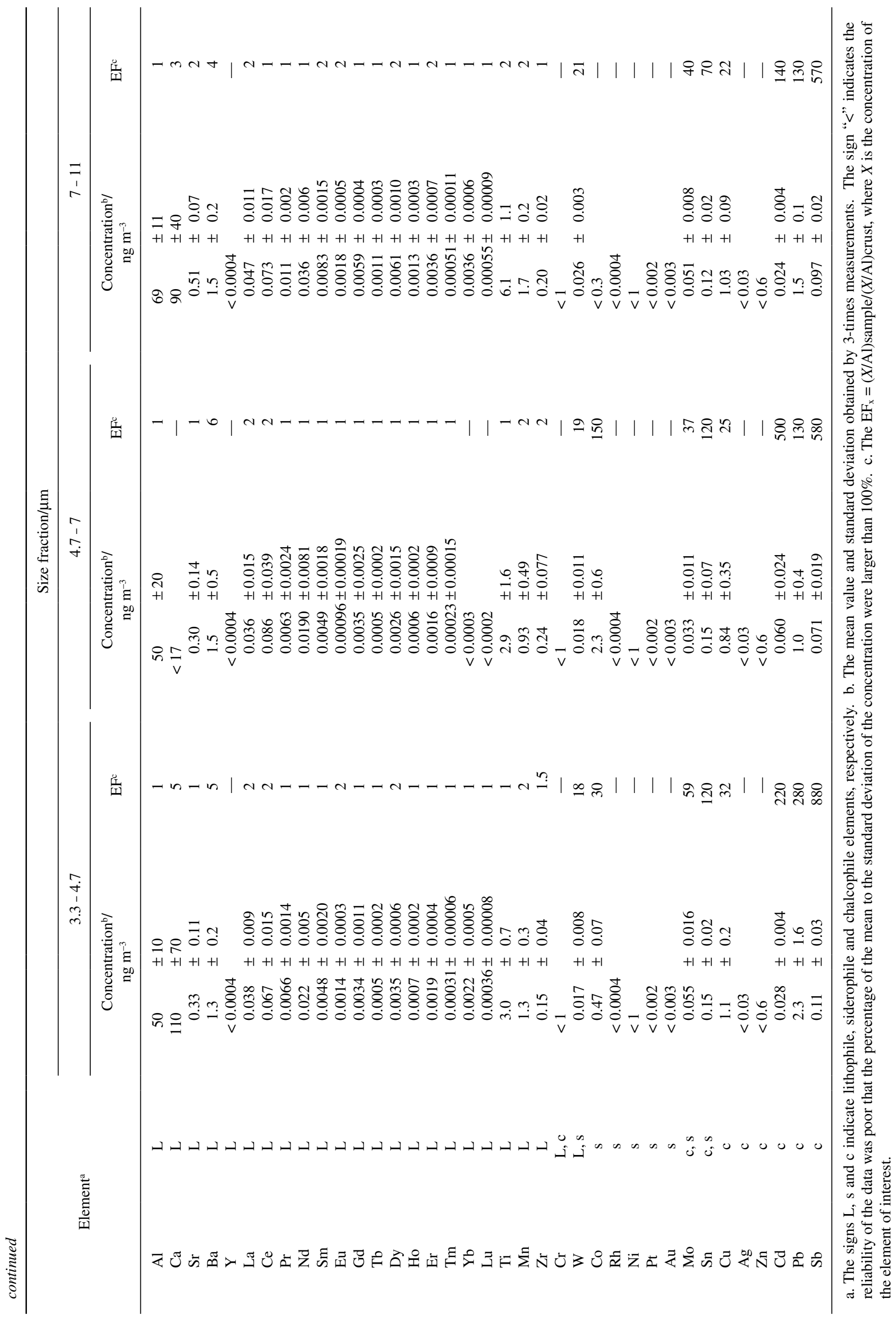




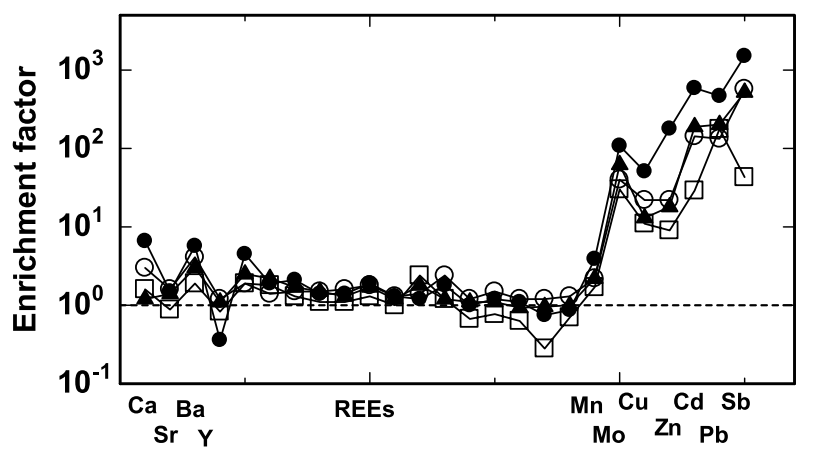

Fig. 1 Comparison of enrichment factors of elements in PM collected at Bucharest and Tokushima. The $\bullet$ and $\bigcirc$ marks indicate the enrichment factor of elements in $1.1-2.1$ and $7-11 \mu \mathrm{m}$ of the size fraction of the PM at Bucharest city in May 23-June 6, 2005, respectively. Those of $\boldsymbol{\Delta}$ and $\square$ indicate the enrichment factor of the elements in $1.1-2.1$ and $7-11 \mu \mathrm{m}$ of the size fraction of the PM at Tokushima cities in May 9 - 23, 2006, respectively.

\section{Conclusion}

In this study, a multielemental analysis method based on microwave-assisted digestion with $\mathrm{HClO}_{4} / \mathrm{HNO}_{3} / \mathrm{HF}$ and ICP-MS/ICP-AES measurement was developed. Thirty nine elements could be determined. Almost all rare-earth elements and noble metals (Au, Pt and Rh) in NIES No. 8 were firstly determined in the present work. The concentration trends among ca. 30 elements in the sample in Bucharest and Tokushima were shown to be significantly different in the chalcophile elements. In further research, we will investigate trends between concentrations of anionic species and heavy elements so as to understand their origins and fates.

\section{Acknowledgements}

The present work was partly supported by Grants-in-Aid of Scientific Research (No. 17750071), from the Ministry of
Education, Culture, Sports, and Science and Technology and a Young Scientist Fellowship from Institute of Science and Technology, The University of Tokushima.

\section{References}

1. J. M. Ondov and A. S. Wexler, Environ. Sci. Technol., 1998, 32, 2547.

2. T. Fukai, T. Kobayashi, M. Sakaguchi, M. Aoki, T. Saito, E. Fujimori, and H. Haraguchi, Anal. Sci., 2007, 23, 207.

3. E. Fujimori, T. Kobayashi, M. Aoki, M. Sakaguchi, T. Saito, T. Fukai, and H. Haraguchi, Anal. Sci., 2007, 23, 1359.

4. N. Furuta, A. Iijima, A. Kanbe, K. Sakai, and K. Sato, J. Environ. Monit., 2005, 7, 1155.

5. A. Iijima, H. Tago, K. Kumagai, M. Kato, K. Kozawa, K. Sato, and N. Furuta, J. Environ. Monit., 2008, 10, 1025.

6. M. Ogaki, K. Yoshizumi, J. Motonaka, T. Yabutani, Y. Nakamoto, R. Stanescu, and M. Plesca, Int. J. Modern Phys. B, 2006, 20, 4243.

7. V. Cercasov, A. Pantelica, M. Salagean, and H. Schreiber, Environ. Pollut., 1998, 101, 331.

8. M. Mihaela, I. Lacatusu, A. Murariu, A. Meghea, and A. Stanescu, Environ. Engineer. Manag. J., 2007, 6, 473.

9. M. Tamaru, T. Yabutani, and J. Motonaka, Bunseki Kagaku, 2004, 53, 1435.

10. S. Akatsuki, R. Yamanouchi, Y. Nakamoto, K. Yoshizumi, M. Ogaki, T. Yabutani, Y. Hayashi, and J. Motonaka, Bunseki Kagaku, 2008, 57, 659.

11. S. Miyata, A. Tanji, H. Imura, H. Matsue, and C. Yonezawa, Bunseki Kagaku, 2006, 55, 689.

12. The report, "Central and Eastern Europe + EECCA Leaded Gasoline Use from United Nations Environment Programme", 2007, http://www.unep.org/pcfv/PDF/ MatrixCEELeadMarch07.pdf.

13. W. H. Zoolder, E. S. Gladney, and R. A. Duce, Science, 1974, 183, 198.

14. K. Sato, T. Tamura, and N. Furuta, J. Environ. Monit., 2008, 10,211 